\title{
Hypothesizing Molecular Genetics of the Holocaust: Were Dopaminergic Genes Involved or Brain Wash?
}

\author{
Kenneth Blum²,3*, Gil Atzmon', David Baron² and RD Badgaiyan ${ }^{3}$ \\ ${ }^{1}$ Departments of Medicine and Genetics, Albert Einstein School of Medicine, Bronx, New York, USA \\ and Departments of Medical Sciences and Human biology Haifa University, Haifa, Israel \\ ${ }^{2}$ Departments of Psychiatry and Behavioural Sciences, Keck School of Medicine, University of \\ Southern California, Los Angeles, CA USA \\ ${ }^{3}$ Department of Psychiatry, Wright State University Boonshoft School of Medicine and Dayton VA \\ Medical Center, Dayton, $\mathrm{OH}$ (IE)
}

Received: September 22, 2016; Accepted: October 05, 2016; Published: October 17, 2016

*Corresponding author: Kenneth Blum, Department of Psychiatry and McKnight Brain Institute, University of Florida, College of Medicine, Administrative Office L5-101, PO BOX 100015, Gainesville, Florida, 32610-0015, USA. Tel: 619-890-2167; Email: drd2gene@gmail.com

\begin{abstract}
Numerous studies indicated that the prevalence of certain alleles of the dopamine D2 receptor gene (DRD2) vary across different ethnic groups. Under adverse environmental conditions, these alleles can increase the risk of developing psychiatric symptoms. Thus, we hypothesized that the prevalence of the DRD2 gene Taq IA allele may serve to explain the horrific behaviours practiced by the Nazi regime. Hitler's 'Brain Washing' methods goaded his followers to carry out genocide at a time when carriers of the DRD2TaqIA allele (the so called 'aggressive--genotype') were significantly higher among the Aryan Germans compared to resident German Jews. It would be of interest, to genotype the Jewish Holocaust survivors, to determine whether those with the $\mathbf{T a q} \mathbf{A I}$ allele survived in greater numbers. The hypothesis being that, greater survival may result in enhanced frequency of not only the DRD2AI allele but other reward gene polymorphisms among survivors. Understanding the molecular genetics of any population in terms of reward dependence and subsequent behaviours will be most beneficial in future human interaction whether negative (war) or positive (peace) in nature.
\end{abstract}

Keywords: Holocaust; Aryan Germans; Jews; dopamine; Reward Dependence; aggression; Molecular Genetics;

\section{Introduction}

While there have been many disciplines represented in genocide studies especially those related to the Holocaust, little has been done with regard to the widely explosive field of Omics. Philosophers have suggested that, in terms of genocide, evil overcomes well [1]. We are cognizant of the importance of philosophical contributions to the key concepts involved in the complexities that underlie human behaviours such as the relationship between the individual and group that are central to the concept of genocide, ethical issues such as intentionality, responsibility, and concepts of good and evil, as well as societal beliefs about genocide [2]. Just as Berel Lang argued that the contribution of professional philosophers to genocide studies could be quite significant [3], we suggest here that molecular- genetic antecedents may also contribute to understanding the atrocities that occurred under the Nazi regime.

The coining of the word 'Genocide' by Raphael Lemkin led to the UN Convention on Genocide in 1948 [4]. His term signified the nullification of any innocent peoples across the globe not only the mass killings of Jews during the Holocaust. Certain countries like the Soviet Union did not treat the mass killings as a uniquely Jewish phenomenon cognizant that other groups were also executed by the Nazis [5].

Hitler's highly successful "Brain Washing" methodology included the: dissemination of well-camouflaged lies (propaganda), harassment of non-believers, intimidation of incorrigible dissidents and finally the elimination of the obstinate recalcitrant and those considered 'unworthy of life'. That many Jewish survivors went on to lead truly successful and fruitful lives attests to the remarkable resilience of the survivors of the Holocaust [6] they developed the 'Holocaust Survivorship Model' that provides an valuable framework, to help us understand how people dealt with trauma, extreme stress and what was required for them to survive, they were then able to find personal meaning in these life events, adapt, and grow [6]. According to the research of Greene's group, about sixty five percent of the Holocaust survivors scored on the high side for resilience traits. According to these investigators, seventy eight percent of the survivors in their study had engaged in processes, considered resilient. They felt they were transcendent, had engaged in behaviours that helped their personal growth and changed them during the years since the Holocaust, so that they were able to leave a legacy and contribute to their communities [6].

\section{Understanding the concept of selfish genes}

A brief description of the evolutionary theory first proposed by Richard Dawkins in his book called 'The Selfish Gene' [7] will help to clarify one focus of this treatise that the gene may be the unit of evolution. Dawkins work builds on the theories of George 
C. Williams from his first book 'Adaptation and Natural Selection' [8].In the 1960s W.D. Hamilton focused on the individual organism and the group rather than the concept proposed by Dawkins a gene-centred theory of evolution whereby the 'selfish gene' is replicated. Interestingly, Dawkins has suggested that from the 'gene-centred' view the more alike two individuals are genetically, the more selflessly they behave toward each other. Moreover, an organism is expected to maximize its fitness for survival by the successful replication of gene copies and rather than, by replication of an individual organism. In simpler terms, Dawkins postulated that the genes within organisms are the replicators, with the body of each organism serving as a 'survival machine' for its genes. Others like Thomas Maschler called it 'the immortal gene' [8, 9]. Finally, Dawkins suggests that successful gene combinations benefit organisms and increase the chances of the gene being propagated. Darwin discussed a theoretical role for a 'Sympatin' gene to ensure evolutionary success; a gene form that promotes survival elements like competitiveness, aggression, and risk taking. Carriers of this gene according to Darwin had a competitive advantage, being not noble and not willing to share but with a better chance of survival [10]. Over 150 years later, this hypothesis is that the 'Sympatin' gene maybe the Taq AI allele a variant of the dopamine D2 receptor (DRD2) gene. In genetic studies the Taq AI allele a variation has been associated with a number of survival-like behaviours $[11,12]$.

\section{Mapping survival--like behaviours and dopaminergic activity}

It is well known that Nazi doctrine was promoted throughout German schools starting at a young age and continuing throughout their secular education. Young Germans were imbued with the ideas of Niche about the Arian super-race. These ideas gave impetus to the attempted annihilation of Jews. However, the potential role of the association of dopamine receptor polymorphisms with childhood aggression may be another important element. In this regard, [13] found that children who carried specific DRD2 gene alleles had significantly increased aggressive behaviour in a Hungarian patient [13].

Imbalances in the central dopamine system including genes that regulate other reward neurotransmitters like serotonin are important in the development of borderline personality disorder. Recently [14] demonstrated that young adult carriers of a number of DRD2 polymorphisms show impulsive and aggressive self-damaging behaviours. While these results are interesting the significant association was with DRD4 -616 CC allele and rs1800497 was not found to have significant association in Hungarian patient group in terms of personality. However other work by Kazantseva et al. [15] shows significant effects of ANKK1/DRD2 Taq1A on Neuroticism $(\mathrm{p}=0.016)$ and of SLC6A3 rs27072 (DAT1) on Persistence ( $p=0.021)$ in both genders. The association between ANKK1/DRD2 Taq1A A2/A2-genotype and higher Novelty Seeking and lower Reward Dependence was shown in men only (p for gender interaction=0.018) [15].

This result is also supported by work from Blum's group, whereby, in a blinded clinical trial, a positive correlation was observed with DRD2 and dopamine transporter (DAT1) gene variations and pathological violence in adolescents [16]. In another study of young adults with extremely aggressive behaviours, the investigators also found a positive correlation with both DAT1 and DRD2 polymorphisms [17]. In addition, similar impulsive behaviours were found in family members of these pro bands suggesting an inherited passage of aggressive -like genes (possibly the 'Sympatin' gene). To be clear while it has been 150 years since Darwin in his works suggested the possibility of a survival gene ('Sympatin' gene) it is proposed herein that the gene referred to be Darwin could be related to the DRD2 A1 allele. However this polymorphism (rs1800497) resides in the ANKK1 gene which interacts with the biological activity of DRD2 receptor [11-13] (also seehttp://www.ncbi.nlm. nih.gov/SNP/snp_ref.cgi?rs=1800497).

It is noteworthy that dopaminergic neurons are involved the behaviour of muricide (killing) rats [18] found that a deficiency of dopamine, determined by chemically induced degeneration of dopamine neurons in the olfactory bulb, may be related to rodent killing aggression in rats. While homicide and aggressive behaviours are multi-factorial, genetics may play a prominent but undetermined role. However, it is becoming clear that the genes that govern reward gene regulation in the limbic system, especially for dopamine and serotonin predispose individuals to homicidal behaviour [19]. Specifically [19] found an association between a variant on the Catechol -Methyl-Transferase (COMT), responsible for clearance of synaptic dopamine, and homicidal behaviour in Schizophrenics. Moreover, [20] systematically showed that four genes involved in dopamine function associated with violent criminal behaviour in boys. Volkow's group was the first to report that variants for the Mono Amine Oxidase A (MAOA) gene that result in an inability to clear dopamine in both the synapse and mitochondria, are associated with aberrant aggression [21]. In contrast, deficits at the molecular level, including carrying the DRD2AI allele, result in low dopamine receptors and a super sensitivity that occurs, when activated by an abusable substance like alcohol, leads to very aggressive behaviour [22-29].

\section{Ethnicity and Dopamine D2 receptor Gene}

The evidence for differences across different ethnic groups in the prevalence of certain alleles of the DRD2 gene is ample. In 1993 [30] reported on population frequencies of the DRD2 Taq AI allele receptor locus. The allelic prevalence significantly varies whereby nine percent of the Yemenite Jews carried the DRD2 Taq AI allele, 6 percent in Ashkenazi Jews, compared to seventyfour percent of the Cheyenne American Indians and twenty-two percent among the German cohort. In fact, one variant of the DRD2 known as the rs6277C $>\mathrm{T}$ associated with addiction risk, was found, in a German population study, to be as high as fiftytwo percent [31].However the National Library of Medicine (NLM) Hapmap Central European (CEU) population frequency of $\mathrm{T}$ allele is also fifty three percent (see http://www.ncbi.nlm. nih.gov/projects/SNP/snp_ref.cgi?rs=6277). Hence the high frequency may not account for Germans only. 
Interestingly, it was also determined that Germans, carrying the DRD2Taq AI significantly associates with extraversion [32]. In addition, it was also determined that German participants characterized by low D2 receptor density in the striatum show a high novelty seeking (thrill) behaviour. Koehler et al [32] and Mongtag et al [33] showed that in German carriers with at least one of the 66Met allele (Val66Met and Met66Met) of the BDNF SNP and one AI allele (AI/AI and AI/A2) of the DRD2 SNP are associated with the lowest grey matter volume of the anterior cingulate cortex, a site for decision making and relapse to addiction. The authors concluded that there might be an increased risk for the development of psychiatric symptoms under adverse environmental conditions. Albeit lack of direct information comparing ethnic groups we propose at the time of Hitler's rise to power, Nazism accelerated pathological aberrant behaviour against not only the Jews but other alleged "misfits" in the German society.

Other factorslend support for emotional pathology in Germans such as alexithymia. Alexithymia, a personality construct, refers to difficulties in emotional self-regulation that contribute as risk factors to several mental disorders manifest when individuals demonstrate an impoverished conscious experience of emotions. Specifically in a study by German scientists Walter et al. found that, on the subscale "Difficulties Identifying Feelings" of the total Toronto Alexithymia Scale, carriers of at least one DRD2/ ANKK1AI allele and one BDNF 66Met, had the highest scores [34, 35]. Although Nazi indoctrination, this interesting molecular genetic fact may have had profound effects on German soldiers taking orders to kill Jews without emotion or guilt about what they have done in the line of duty. A plausible molecular -genetic hypothesis of the holocaust.

We are hereby proposing that based on this knowledge regarding molecular genetics and potential links to certain behaviours including drug seeking, aggression and even homicide in different ethnic groups we propose, the higher prevalence of the DRD2 AI, the more likely is the tendency to display these behavioural characteristics. Carriers of the DRD2 A1 allele would have enhanced drug seeking including alcohol, and as such could become involved in violent acts, due in part, to build up of a known violent substance called Diazepam -Binding -Inhibitor (DBI) which increases post alcohol intake [27-29].The main focus of the hypothesis, however, remains the higher frequency of the so called 'aggressive--genotype'. It is noteworthy, that in spite of Hitler's objection to any substance (tobacco, drugs and alcohol use especially in the military), there are accounts of alcohol abuse and abusive behaviour by German Soldiers [36]. Although, the German soldiers in general were not part of the Holocaust action which was driven by the SS soldiers who acted like emotionless -robots potentially due to 'aggressive-genotypes' with or without alcohol as a confounding variable.

Therefore, in accordance with this hypothesis it seems reasonable that Aryan Germans would have displayed these behavioural characteristics to a greater degree than would have German Jews. Keeping in mind that there are no records of genotyping during the early thirties, we must make assumptions which may provide an appropriate snapshot. It is wellestablished that severe Alcoholism has been associated with the Taq AI allele of the DRD2 gene in the American population at a high rate. Therefore, when in 1982, for example, Snyder et al. evaluated alcoholism among the Jews in Israel who were descendants of Jewish Holocaust survives who had migrated to Israel and compared to other major either communities, found that Ashkenazi Jews have a significantly lower rate of alcoholism than both the Sephardi and Oriental groups [36]. While there are certain environmental mores (epigenetic) that load onto this, it is potentially important that various ethnic populations (Jews vs. non-Jews) may be at a higher or lower risk for a number of RDS behaviours including alcoholism depending on certain reward gene polymorphisms such as carrying the DRD2 Taq AI [37].

Israel in1997, in terms of homicide rates, was amongst the top five safest countries in the world, compared to Germany, where Berlin, was amongst the top twenty worst cities in the world for homicide. However in Israel, for example, the homicide rate produced by criminal activities is relatively low: 2.4 killed per 100,000 inhabitants in a year much lower than most countries studied [38].

We are proposing that many of the Jewish survivors of the Holocaust would have carried the DRD2Taq AI when they immigrated to Israel in the 1940's. The Israelis of today would have an increased Taq AI allele prevalence and behave quite differently, more like their Aryan German counterparts during the Holocaust period. A search in the current literature did not provide any evidence of genotyping in surviving Jews and we cannot know unless we genotype holocaust survivors and their respective children. However, there may be some facts which could be argued in favour of investigating the possibility of enhanced DRD2Taq AI allele frequency in the Israel population of the $21^{\text {st }}$ century.

Certainly, we have seen a lot of evidence that the current day Israelis defend themselves against enemy attacks of neighbouring Arab territories and aggression even in daily life. It is noteworthy that, in 1995 , the German per 100,000 capita homicide rate was 1.7 while the Israeli per 100,000 capita homicide rate was slightly higher at 2.0. The homicide rate for Israel reached its highest rate of 3.6 in 2001 and by 2011 had dropped to 2.0 again. The homicide rate for Germany dropped to 0.8 in 2011 [39]. These numbers might reflect genetic loading in Israel for carrying the aggressive Taq AI allele genotype, although untested. It is equally arguable that this increase in murders by the populous, which has always included genetically unrelated Palestinians, could be due to non-genetic reasons including stress, military training, war, economics, and other environmental epigenetic elements.

\section{A caveat}

It is noteworthy that DNA from the modern Jewish population has not as yet been compared to ancient Judean DNA in any studies. In the absence of old DNA, geographic roots can be traced adequately using data from living populations [40, 41, 42]. Population genetics such as the Founder Effect; the presence of a selectively neutral, identical by descent allele at a high frequency 
in an isolated population that was carried by a founder individual or arose by later mutation, can be useful in data extrapolation. Indeed the data from living populations is in agreement with key Jewish historic events. There are traces of Northern Italian and Slavic ancestry among European Jews because intermarriage occurred before the Roman Empire outlawed conversion to Judaism. Some Ashkenazi ancestral lines in Southern European families come from these marriages. Finally, a perfect genetic corollary of Ashkenazi Jewish ancestry was demonstrated by [42] within Americans of European ancestry. Indeed, a single Jewish grandparent can be distinguished statistically from individuals without Jewish ancestry. We now know that the first migration of people out of Africa to Israel occurred over 63,000 years ago. However, to date no one has genotyped the ancestral Jewish DNA to determine whether the oldest Jews carried a higher rate of the aggressive Taq AI allele genotype which could have increased their survival chance.

\section{Conclusion}

Limited by the absence of DRD2 Taq AI allele genotyping among the Jewish Holocaust survivors as well as the Nazis SS soldiers we can only hypothesize, based on recent studies in human and animal models, about the link between genetic predisposition and the horrific behaviours perpetrated during the Holocaust. However, it seems fairly convincing that during the period of the Holocaust that the differential in carriers of the DRD2 Taq AI allele (the so--called aggressive genotype) estimated by the older work of Barr and Kidd [30] that there was a higher percentage of DRD2A1 allele among the Aryan Germans compared to residential German Jews. It would be important to genotype holocaust surviving Jews across the world to determine whether there has been an enhanced frequency of not only the DRD2AI allele but other reward genes, including serotonin, endorphin, GABA and other dopamine polymorphisms $[43,44,45]$. However finding such an enhanced frequency may not provide all the answers especially when you consider the environmental-epigenetic psychological factors including "brain washing" as a precursor for extermination practiced in the Nazi regime

While there is a plethora of evidence for Hitler's brain washing and resultant devastation of all Germans, [46] understanding the molecular genetics of any population in terms of reward dependence and subsequent behaviour will be most beneficial in future human interaction, both when negative and positive in nature [47].

\section{Acknowledgements}

The authors appreciate the editorial assistance of Margaret A. Madigan. Kenneth Blum, PhD is the recipient of a grant from Life Extension Foundation of Ft. Lauderdale Florida awarded to Path Foundation NY. Gill Aztmon is the recipient of1R01AG042188. Rajendra D. Badgaiyan is supported by the National Institutes of Health grants 1R01NS073884 and 1R21MH073624; and VA Merit Review Awards CX000479 and CX000780.

Conflict of Interest: There are no conflicts of interest to report.

\section{References}

1. RJ Bernstein. Hannah Arendt and the Jewish Question. 1996;137.

2. Schott RM. War rape, nationality and genocide. Journal of Genocide Research. 2011;13(1-2):5-21.

3. Lang B. Philosophy's contribution to Holocaust studies. in Eve Garrard and Geoffrey Scarre (eds), Moral Philosophy and the Holocaust Aldershot: Ashgate, 2003;1-8.

4. Stone D. Raphael Lemkin on the Holocaust. Journal of Genocide Research. 2005;7(4):539-550.

5. Asher H. The black book and the Holocaust. Journal of Genocide Research.1999;1(3):401-416. Doi:10.1080/14623529908413969.

6. Greene RR, Hantman S, Sharabi A, Cohen H. Holocaust survivors: three waves of resilience research.Journal of Evidence Based Social Work, 9(5):481-497. doi:10.1080/10911359.2011.566797.

7. Gould SJ. Caring Groups and Selfish Genes, The Panda's Thumb: More Reflections in Natural History. Harmondsworth: Penguin Books. $1990 ; 72-78$.

8. Dawkins R. It's all in the genes. The Sunday Times. 2006.

9. Eldredge N. Why We Do It: Rethinking Sex and The Selfish Gene New York City: W.W. Norton\& Co., 2004;233.

10. Darwin C. On the Origin of Species by Means of Natural Selection, or the Preservation of Favored Races in the Struggle for Life. Nature $1^{\text {st }}$ ed. London: John Murray. 1859; doi:10.5962/bhl.title.68064.

11. Noble EP, Blum K, Ritchie T, Montgomery A, Sheridan PJ. Allelic association of the D2 dopamine receptor gene with receptor-binding characteristics in alcoholism. Arch Gen Psychiatry. 1991;48(7):648654

12.Williams J, Taylor E. The evolution of hyperactivity, impulsivity and cognitive diversity. J R Soc Interface. 2006;3(8): 399-413. DOI:10.1098/rsif.2005.0102.

13.Zai CC, Ehtesham S, Choi E, Nowrouzi B, de Luca V, Stankovich L, et al. Dopaminergic system genes in childhood aggression: possible role for DRD2. World J.Biol Psychiatry. 2012;13(1): 65-74. doi:10.3109/1562 2975.2010.543431

14.Z Nemoda, K Lyons-Ruth, A Szekely, E Bertha, G Faludi, M SasvariSzekely. Association between dopaminergic polymorphisms and borderlinepersonality traits amongat-riskyoung adults and psychiatric inpatients. Behav Brain Funct. 2010;6:4. DOI:10.1186/1744-9081-6-4

15. Kazantseva A, Gaysina D, Malykh S, Khusnutdinova E. The role of dopamine transporter (SLC6A3) and dopamine D2 receptor/ ankyrin repeat and kinase domain containing 1 (DRD2/ANKK1) gene polymorphisms in personality traits. Prog Neuro psycho pharmacol Biol Psychiatry. 2011;35(4):1033-1040. doi:10.1016/j. pnpbp.2011.02.013.

16. TJ Chen, K Blum, D Mathews, L Fisher, N Schnautz, ER Braverman, et al. Are dopaminergicgenesinvolved in a predisposition to pathological aggression? Hypothesizing the importance of super normal controls in psychiatric genetic research of complex behavioral disorders. Med Hypotheses. 2005;65:703-707. DOI:10.1016/j.mehy.2005.04.037.

17. TJ Chen, K Blum, D Mathews, L Fisher, Nancy Schnautz, ER Braverman, et al. Preliminary association of both the Dopamine D2 Receptor (DRD2) [Taq1 AI Allele] and the Dopamine Transporter (DAT1) [480 bp Allele] genes with pathological aggressive behavior, a clinical subtype of Reward Deficiency Syndrome (RDS) in adolescents. Gene Therapy and Molecular Biology. 2007;11:93-112. 
18. T Tadano-Adano, Y Abe, Y Morikawa, T Asao, M Hozumi, N Takahashi, et al. Involvement of dopaminergic neurons in mouse killing aggression in rats. Methods and Findings in Experimental and Clinical Pharmacology. 1997;19(8):527-531.

19. M Kotler, P Barak, H Cohen, IE Averbuch, A Grinshpoon, I Gritsenko, et al. Homicidal behavior in schizophrenia associated with a genetic polymorphism determining low catechol 0-methyltransferase (COMT) activity. Am J Med Genet. 1999;88(6):628-633.

20.EL Grigorenko, CG De Young, M Eastman, M Getchell, GJ Haeffel, B Klinteberg, et al. Aggressive behavior, related conduct problems, and variation ingenes affecting dopamine turnover. Aggress Behav. 2010;36:158-176. doi:10.1002/ab.20339.

21. Nelly Alia-Klein, Rita Z Goldstein, Aarti Kriplani, Jean Logan, DardoTomasi, BenjaminWilliams, et al. Brain monoamine oxidase A activity predicts traitaggression. J Neurosci. 2008;28(19):5099-5104. doi:10.1523/JNEUROSCI.0925-08.2008.

22. TJ Chen, BW Downs, A Bowirrat, RL Waite, ER Braverman, MA Madigan, et al. Neuro genetics of dopaminergic receptor super sensitivity in activation of brain reward circuitry and relapse: proposing deprivation-amplification relapse therapy (DART). Postgrad Med. 2009;121(6):176-196. doi:10.3810/pgm.2009.11.2087.

23. P Seeman. Schizophrenia thalamus imaging: Low benzamide binding to dopamineD2receptorssuggests fewer D2Shortreceptorsand fewer presynaptic terminals. Psychiatry Res. 2013;214(3):175-180. doi:10.1016/j.pscychresns.2013.09.013

24. Kenneth Blum, EP Noble,PJ Sheridan,Anne Montgomery, Terrie Ritchie, Pudur Jagadeeswaran, et al. Allelic association of humandopamine D2 receptorgene in alcoholism. JAMA. 1990;263(15):2055-2060.

25. Kenneth Blum, AL Chen, Merlene Oscar-Berman, TJ Chen, JoesephLubar, NW Lubar Judith, et al. Generational association studies of dopaminergic genes in reward deficiency syndrome (RDS) subjects: selecting appropriate phenotypes for reward dependence behaviors. Int J Environ Res Public Health. 2011;8(12):4425-4459. Doi:10.3390/ ijerph8124425.

26. CE Bass, VP Grinevich, Dominic Gioia, JD Day-Brown, KD Bonin, GD Stuber, et al. Optogenetic stimulation of VTAdopamine neurons reveals that tonic but not phasic patterns of dopamine transmission reduce ethanol self-administration. Front Behav Neurosci. 2013;7:173. doi:10.3389/fnbeh.2013.00173.

27.Eminio Costa and Alessandro Guidotti. Neuropeptides are cotransmitters: modulatory effects of GABAergic synapses. in Herbert Y. Melzer (ed.),Psychopharmacology: the third generation of progress (New York: Raven Press)1987;425-435.

28. Patrizia Ferrero, BM Conti-Tronconi, Alessandro Guidotti. DBI an anxiogenic neuropeptide found in human brain. Adv Biochem Psychopharmacol. 1986;41:177-185.

29. H Alho, M Miyata, E Korpi, K Kiianmaa, Alessandro Guidotti. Studies of a brain polypeptide functioning as a putative endogenous ligand to benzodiazepine recognition sites in rats selectively bred for alcohol related behavior. Alcohol Alcohol. 1987;1(Suppl.1):637-641.

30. CL Barr, KK Kidd. Population frequencies of the AI allele at the dopamine D2 receptor locus. Biol Psychiatry. 1993;34(4):204-209. doi:10.3389/fnbeh.2013.00173.

31. Alexandra Doehring, Anja Kirchhof, Jorn Lötsch. Genetic diagnostics of functional variants of the human dopamineD2receptor gene. PsychiatrGenet. 2009;19:259-268. doi:10.1097/ YPG.0b013e32832d0941.

32. S Koehler, J Wacker, T Odorfer, Andreas Reif, J Gallinat, AJ Fallgatter, et al. Resting posterior minus frontal EEG slow oscillations is associated with extraversion and DRD2 genotype. Biol Psychol. 2011;87(3):407413. DOI:10.1016/j.biopsycho.2011.05.006.

33. Christian Montag, Sebastian Markett, Ulrike Basten, Stelzel ChristianFiebach, Turhan Canli, Martin Reuter. Epistasis of the DRD2/ANKK1 Taq Ia and the BDNF Val66Metpolymorphismimpacts novelty seeking and harm avoidance. Neuro psychopharmacology. 2010;35(9):1860-1867. doi:10.1038/npp.2010.55

34. Christian Montag, Bernd Weber, E Jentgens, C Elger, MartinReuter. An epistasis effect of functional variants on the BDNF and DRD2 genes modulates gray matter volume of the anterior cingulate cortex in healthy humans. Neuropsychologia. 2010;48(4):1016-1021. doi:10.1016/j.neuropsychologia.2009.11.027.

35. NT Walter, Christian Montag, Sebastian Markett,Martin Reuter. Interaction effect of functional variants of the BDNF and DRD2/ ANKK1geneis associated with alexithymia in healthy human subjects. Psychosom Med. 2011;73(1):23-28. doi:10.1097/ PSY.0b013e31820037c1.

36. CR Snyder, P Palgi, P Eldar, B. Elian. Alcoholism among the Jews in Israel: a pilot study. I. Research rationale and a look at the ethnic factor. J Stud Alcohol. 1982;43(7):623-654

37. Blum K, Gold. Neuro-chemical activation of brain reward meso-limbic circuitry is associated with relapse prevention and drug hunger: a hypothesis. Med Hypotheses. 2011;76(4):576-584. doi:10.1016/j. mehy.2011.01.005.

38. The 2011 Global study on homicide was prepared by the Statistics and Surveys Section under the supervision of Sandeep Chawla, Director, Division for Policy Analysis and Public Affairs. Copyright 2011 C United Nations Office on Drugs and Crime (UNODC). 2013.

39. TD Miethe, WC Regoeczi, KA Drass. Rethinking Homicide: Exploring the structure and process underlying deadly situations. Cambridge: Cambridge University Press. 2011

40. MF Hammer, AJ Redd, ET Wood, MR Bonner, H Jarjanazi, T Karafet, et al. Jewish and Middle Eastern non-Jewish populations share a common pool of Y-chromosome biallelic haplotypes. Proc Natl Acad Sci. U SA. 2000;97(12):6769-6774.

41. Gil Atzmon, Li Hao, Itsik Peer, Christopher Velez, Alexander Pearlman, Pier Francesco Palamara, et al. Abraham's children in the genome era: major Jewish diaspora populations comprise distinct genetic clusters with shared Middle Eastern Ancestry. Am J Hum Genet. 2010;86(6):850-859. doi:10.1016/j.ajhg.2010.04.015.

42. AC Need, D Kasperaviciute, ET Cirulli, DB Goldstein. A genome-wide genetic signature of Jewish ancestry perfectly separates individuals with and without full Jewish ancestry in a large random sample of European Americans. Genome Biol. 2009;10:R7. DOI:10.1186/gb2009-10-1-r7.

43. The Nazi Death Machine: Hitlers drugged soldiders. 2013.

44. HR Luo, ZF Hou, J Wu, YP Zhang, YJ Wan YJ. Evolution of the DRD2genehaplotype and its association with alcoholism in Mexican Americans. Alcohol. 2005;36(2):117-125. DOI:10.1016/j. alcohol.2005.09.003

45. Frances Calafell, EL Grigorenko, AA Chikanian, KK Kidd. Haplotype evolution and linkage disequilibrium: A simulation study. Hum Hered. 2001;51(1-2):85-96.

46. BRAINWASHING: Hitler used same techniques- Letters to the Editor New Straits Times. 2013

47. Kenneth Blum, PJ Sheridan, T Chen, RC Wood, ER Braverman, JG Cull, DE Comings. Chapter 24: The Dopamine D2 Receptor Gene Locus in Reward Deficiency Syndrome: Meta -Analyses. In Handbook of Psychiatric Genetics Kenneth Blum and Earnest P. Noble (eds.)Boca Raton. New York and London: CRC 